\title{
Quality and abortion services
}

\section{Jonathan Lord}

Consultant Gynaecologist, Royal Cornwall Hospital, Truro, UK

\section{Correspondence to}

Mr Jonathan Lord, Department of Obstetrics and Gynaecology, Royal Cornwall Hospital, Truro TR1 3LJ, UK; j.lord@exeter.ac.uk

Received 13 September 2016 Accepted 30 November 2016

\section{SLinked}

http://dx.doi.org/10.1136/ jprhc-2015-101427

\section{CrossMark}

To cite: Lord J. J Fam Plann Reprod Health Care 2017:43:16-17.
The authors of the article 'Identifying indicators for quality abortion care: a systematic literature review' in this journal issue $^{1}$ deserve admiration for having proposed an academic solution to address the paucity of work in this area. It is telling that only 21 relevant publications could be identified in the literature, despite abortion being such a common health need that a significant proportion of the population will access. In other areas of medicine the quality agenda has become mainstream. In contrast, those involved in abortion care frequently work in isolation and have had to concentrate on operating in difficult legal and social environments where defined quality indicators could be used against them further to restrict access. It is therefore heartening to see this article published - are we at last moving beyond simply being grateful that there is a service at all, and becoming eager to take the initiative for genuine quality improvement?

A lack of clarity in definitions has not helped the quality agenda. One of the key documents from the UK that sought to address this, ${ }^{2}$ and that is now enshrined in law through the Health and Social Care Act 2012, describes three essential elements: providing care that is safe, effective and delivers a positive patient experience. ${ }^{3}$ In defining the quality standards that enable this, the National Institute for Health and Care Excellence (NICE) states that these should be "aspirational, but achievable, markers of high-quality, cost-effective patient care". 4

As Dennis et al. ${ }^{1}$ point out, there is little agreement as to what constitutes quality abortion care, and there is a need to develop a streamlined set of indicators. Such indicators need to be important to patients, clinically relevant, measurable, accessible for benchmarking, and agreed by consensus. Some measures will be more relevant to policymakers and commissioners of services, others to patients and to staff providing the service. In
October 2015, the British Society of Abortion Care Providers (BSACP) ${ }^{5}$ held its inaugural conference at which a top five' were proposed for the UK:

- Percentage of all National Health Service (NHS) funded abortions being performed at under 10 weeks' gestation. This is an excellent general system efficiency measure, and has been routinely collected and published for years in England and Wales.

- Access to appropriate choice of procedure (medical, surgical under local and general anaesthetic) with evidence of efficient shared-care pathways if the procedure of choice is not provided where the patient presents.

- Waiting times within Royal College of Obstetricians and Gynaecologists (RCOG) standards of $<1$ week for assessment and 1 week for treatment where desired by the patient. $^{6}$

- Measures of quality of care from patientreported outcomes (e.g. satisfaction surveys).

- Engagement in quality assurance processes such as peer review and publishing results, including key quality parameters such as readmission rates.

There have been successes from equivalent but longer-established specialist societies. For example, the colposcopists' association (BSCCP) has had a major role in the development of the NHS cervical screening quality assurance programme, and in gynaecological endoscopy (BSGE) and urogynaecology (BSUG) the societies administer national databases that are now embedded in NICE guidance. It is extraordinary that the NHS has never developed its own guidelines or quality criteria for abortion, given the large number of patients affected and the lack of integration in care that exists. Even today NICE has abortion services on a 'to do' list awaiting prioritisation from the government. Setting valid quality criteria at national or international level is well overdue. Patients deserve somebody to champion quality in abortion services, and specialty organisations like the new BSACP would seem the ideal candidates to do so. 
Competing interests JL is the lead for quality and doctors' representative on the Council of BSACP.

Provenance and peer review Not commissioned; internally peer reviewed.

\section{REFERENCES}

1 Dennis A, Blanchard K, Bessenaar T. Identifying indicators for quality abortion care: a systematic literature review. J Fam Plann Reprod Health Care 2017;43:7-15.

2 Department of Health. High Quality Care for All. NHS Next Stage Review Final Report (CM7432). 2008. http://www.gov.uk/ government/uploads/system/uploads/attachment_data/file/ 228836/7432.pdf [accessed 20 November 2016].

3 Monitor. Quality Governance: How Does a Board Know that its Organisation is Working Effectively to Improve Patient Care?
Guidance for Boards of NHS Provider Organisations. 2013. http://www.gov.uk/government/uploads/system/uploads/ attachment_data/file/284262/ToPublishQualityGovGuide 22April13FINAL.pdf [accessed 20 November 2016].

4 National Institute for Health and Care Excellence (NICE). NICE Glossary. 2016. http://www.nice.org.uk/Glossary? letter $=\mathrm{Q} \#$ Quality\%20standards [accessed 20 November 2016].

5 British Society of Abortion Care Providers (BSACP). https:// bsacp.org.uk/ [accessed 20 November 2016].

6 Royal College of Obstetricians and Gynaecologists (RCOG). The Care of Women Requesting Induced Abortion (Evidence-based Clinical Guideline No. 7). 2011. http://www.rcog.org.uk/globalassets/documents/ guidelines/abortion-guideline_web_1.pdf [accessed 20 November 2016].

\section{Seen through fresh eyes}

It was quite an introduction to sexual and reproductive health for the work experience student. The nursing staff had managed to encourage the lady with severe mental health problems to stay for the community intrauterine device (IUD) clinic. She had presented to the walk-in clinic on several previous occasions requesting infection screening and hormonal emergency contraception. Her pronounced anxiety kept the health care assistant (HCA) and Jenny, the student, fully occupied with reassurance, conversation and hand-holding while the IUD insertion took place. Later that same afternoon, several women talked of difficulties with their relationships, and another patient confided to us about the struggle of daily life as the carer for her child with a learning disability.

Jenny's personal statement for medical school application included her feelings about the clinic experience: "In the community, I noticed a different atmosphere from the acute wards. The woman who, after an IUD fitting in a sexual health clinic, disclosed her anxieties about her learning disabled son, demonstrated a hugely important non-clinical role for a medic, that of confidant".

The clinics, as seen through another's eyes, made me appreciate anew what a hugely privileged position we are when the patients' confidence and trust allows doctor, HCA and student to listen to and share their worries and concerns.

Margaret Tasker, Specialty Doctor, Leigh Shine Clinic, Wigan and Leigh Centre for Sexual and Reproductive Health, Leigh, and Forensic Physician, St Mary's Sexual Assault Referral Centre, Manchester, UK

Jennifer Hobbiss, BA, Medical Student, University of Manchester, Manchester, UK 